\title{
O ESTÁGIO ÚLTIMO DO CAPITAL. A CRISE E A DOMINAÇÃO DO CAPITAL FINANCEIRO NO MUNDO
}

\author{
Jorge Nóvoa* \\ Paulo Balanco*
}

\begin{abstract}
Nos limites deste artigo, analisaram-se os vários elementos da onda de transformações ocorridas no âmbito da economia capitalista mundial nos últimos decênios. Estas resultaram de medidas contra tendências, visando ao bloqueio e à superação da crise estrutural decorrente do esgotamento do crescimento de longa duração do pós-Segunda Grande Guerra. Contraditoriamente, ao tempo em que as mudanças introduzidas se revelaram poderosas alavancas inovadoras nos planos produtivo e financeiro, também carregaram conteúdos profundamente regressivos. Transformou-se profundamente o capitalismo, mas sem a consolidação de uma nova base sólida para remunerar crescentemente o grande capital, em substituição ao ciclo fechado no início dos anos 1970. Os países "subdesenvolvidos" e "emergentes" reproduzem, com algumas especificidades, tais contradições sob a dominação do capital financeiro. Por conseguinte, o novo modelo de reprodução do capitalismo do tempo presente exibe limites visíveis. Prolonga a crise orgânica que se desdobra em regressões ameaçadoras aos destinos da humanidade, mas não sem criar novas bases para uma superação anticapitalista.

Palavras-chave: Crise Profunda. Capital Financeiro. Lucros Decrescentes. Países Emergentes. Base Alternativa de Acumulação.
\end{abstract}

\section{INTRODUÇÃO}

O processo de desenvolvimento capitalista, posterior à Segunda Guerra Mundial, e que passou à história com o título sugestivo dos Trinta Gloriosos, encontrou seu fim no início dos anos 1970. Ao longo do referido período, o mundo viu se desenvolver o american way of life (o jeito americano de viver) como paradigma econômico-cultural nos EUA, expressando um modelo comportamental no qual a classe trabalhadora foi integrada, alimentando aspirações de classe média e agindo mediante esta mesma assimilação ideológica. Não por acaso, os operários e trabalhadores americanos - excetuando-se alguns setores, como os célebres portuários, raramente aparecem na história dos últimos 60 anos, opon-

* Doutor em Sociologia. Professor do Departamento de Sociologia e da Pós-Graduação da Universidade Federal da Bahia UFBA. Professor Convidado da Université de Paris III Sorbonne.

Estrada de São Lázaro, 197. Cep: 40210-730 - Federação Salvador - Bahia - Brasil. jlbnovoa@yahoo.com.br

* * Doutor em Economia. Professor do Departamento de Economia da UFBA. Atual diretor da mesma faculdade. balanco@ufba.br do-se ao establishment dos mecanismos tradicionais de luta dos assalariados, como as manifestações e greves, diferentemente do que ocorreu na Europa e mesmo no chamado Terceiro Mundo. Nos EUA, tal modelo, por meio de seus mecanismos materiais e subjetivos, foi extremamente eficaz, muito mais do que em outras áreas do planeta, como no caso da Europa.

Na verdade, o processo de integração da classe operária americana à classe média pode ser considerado uma reedição de algo semelhante ao que havia acontecido na Alemanha do final do século XIX e, sobretudo, do início do século XX. Tal processo levou Edward Bernstein, líder herdeiro e teórico reformista da socialdemocracia, a prognosticar o fim da revolução socialista e mesmo sua inutilidade, vez que, supostamente, a classe trabalhadora não manifestava interesse em transformar a base objetiva e material na qual nascera e se desenvolvera. Para tal leitura, os operários alemães queriam ascender à "classe média”, adaptando-se às luzes da cidade e buscando usufruir de tudo que o mundo capitalista pudesse traduzir em reformas e conquistas ma- 
teriais no seu interior para a elevação de seus níveis de vida (Collin, 2009). Se existe uma dose de verdade na compreensão da consciência social da classe trabalhadora alemã do período, há, também, uma superestimação das condições do desenvolvimento capitalista e uma subestimação de suas contradições reais. Entre os anos 1910 e 1914, as crises dos modelos de reprodução dos capitais alemães e europeus se encarregaram de colocar por terra, não apenas as formas sociais que se desenvolveram objetivamente, mas, também, as consciências ideológicas que as acompanhavam, e que, mais tarde, renasceriam nos anos posteriores ao Tratado de Versalhes - particularmente nos anos 1930, sob a inspiração dominante na Alemanha, já não mais da socialdemocracia, mas sim, do nacional-socialismo. Esse renascimento é bem conhecido. Na versão alemã, ocorreu fundado em uma determinada vertente de capitalismo de estado, em cujo âmago se encontrava um processo de militarização do trabalho, uma economia de armamentos e, finalmente, uma economia de guerra, arrastando grandes massas de trabalhadores que se submetem quase completamente aos interesses das frações dominantes do capital e de seus "representantes" no poder.

Ao longo dos diversos períodos do desenvolvimento capitalista, desde os fins do século XIX, viu-se a afirmação progressiva da fusão das frações dominantes do capital numa síntese constitutiva denominada, a partir de determinados critérios, de capital financeiro. Entretanto, tal movimento expressa a reação dos capitais em geral à ação incontornável da lei da queda tendencial da taxa de lucro, fenômeno maior identificado por Marx, que, nessa fase, se manifesta com grande intensidade.

Fundamentalmente, o desenvolvimento capitalista é impulsionado pelos capitais privados em concorrência entre si e pela apropriação da parcela mais elevada possível da mais-valia social. Ocorre que a concorrência se efetiva mediante uma tendência permanente à introdução de inovações tecnológicas como pressuposto para que cada capital individual possa desfrutar, ao menos temporariamente, de vantagens competitivas frente aos seus concorrentes. Por essa razão, os capitais têm uma tendência a se atraírem, visando à constituição de unidades produtivas de maior porte, com as quais obtêm ganhos de escala, dando margem a um fenômeno, também teorizado por Marx, denominado de centralização do capital. A reunião desses capitais resulta em fusões e aquisições, tradicionalmente na esfera produtiva, desdobrando-se, posteriormente, particularmente no período em questão, na integração entre capitais industriais e capitais bancários mediante o emprego do formato das sociedades por ações, as sociedades anônimas. Este formato facilita a fusão, pois permite o acesso mais rápido e em maior escala ao capital de financiamento para alavancar a constituição das novas empresas em tamanho ampliado.

Dentre esses capitais, alguns mais fortes compreendem que a fusão é a única forma para se tornarem "imunes" à concorrência e à crise. Por isso o capital financeiro termina adquirindo certa "independência" em relação aos setores diretamente produtivos. Seus interesses e cálculos serão efetuados, serão, cada vez mais, em função de uma lucratividade que tem por aspiração a liquidez imediata de seus rendimentos. Para tal, eliminam, progressivamente, na medida do possível, o contato com a produção. Marx dirá que se trata de uma aspiração que surgiu com o próprio capital e, de forma precursora, já se encontrava presente nos primeiros "emprestadores" de dinheiro, quando procuravam realizar, ainda que em pequena dimensão, a operação representada na fórmula D-D', que se tornaria, posteriormente, o fetiche dos fetiches do capital financeiro. Não é preciso relembrar quão avassaladora se tornará a concorrência entre capitais, sobretudo durante o século XX.

Se a crise do início dos anos 1970 fecha um ciclo longo de trinta anos de gloriosa lucratividade para o grande capital em geral, ao demolir os acordos que regulavam os fluxos monetários do sistema financeiro internacional - mesmo que com vantagens para o dólar e para a potência 
dominante do capitalismo, ao desvincular sua moeda do padrão ouro os EUA instituíram um padrão que se tornou dominante até hoje, mas acarretando, também, uma espiral de contradições. O novo padrão, que representava a substituição do sistema de câmbio fixo pelo sistema de câmbio flexível, mostrou-se bem mais adequado à pavimentação do terreno para a denominada "desregulamentação" e implantação dos mecanismos de flexibilização produtiva e de mercados, que acabou por estabelecer os contornos do que passaria a ser chamado de neoliberalismo e de globalização.

Com este novo patamar de desenvolvimento, e em função das dificuldades crescentes de remuneração que os capitais enfrentavam no sistema diretamente produtivo, o modelo prioritário de remuneração passou a ser aquele que viabilizava a aplicação de mecanismos super maximizadores de transferência de rendas e mais-valia, seja diretamente dos assalariados do planeta inteiro, seja das diversas instituições dos estados-nação, ou indiretamente de todos os setores sociais, mesmo que com disputas entre as frações diversas dos capitais. Afora os setores legais de altíssima rentabilidade e de remuneração garantida do mega capitalismo (armamentos, químicos, eletrônica e microprocessadores), as diversas frações do capital demonstram pouco interesse em fazer a roda da história retroceder e voltar a investir nos setores produtivos de mercadoria. Todavia, tal cenário também significa o assentamento de um limite histórico para o capitalismo pela simples razão de que, por representar uma cadeia de exploração, o capital financeiro, mesmo desprezando a produção - e se autonomizando perante ela, não pode viver sem a mais-valia explorada diretamente dos trabalhadores assalariados, que foi sendo acumulada historicamente ao longo dos séculos e que se transformou em trabalho morto, assim como daquela que se extrai de diversos modos (inclusive através de esquemas de superexploração) em todas as formações sociais que integram o sistema capitalista internacional.

\section{O CONTEXTO HISTÓRICO-CONJUNTURAL QUE CONDICIONAA CRISE ATUAL}

Durante o ano de 2007, a palavra crise retornou ao vocabulário dos meios de comunicação e da imprensa internacional de maneira tão intensa quanto ressurgira em conjunturas anteriores, sucedidas ao longo do período que se abre a partir do início anos 1970. Evidentemente, não se tratava, naquelas situações conjunturais, de meras especulações movidas por fatores subjetivos, mas, sim, da abordagem de eventos e episódios decorrentes de fatos que se manifestavam de forma real no plano concreto da economia. Tal regularidade econômica das últimas décadas, inerentemente associada ao vocábulo "crise", exige que se explique porque, muito embora a mesma seja considerada um fenômeno econômico ordinário do capitalismo, sua aparição ocorra, agora, de modo recorrente em situações nas quais, aparentemente, não deveria surgir.

De fato, a regularidade da crise nos tempos atuais acontece em meio a profundas contradições. Pode ser afirmado, em primeiro lugar, que o novo cenário se instala após o mergulho do capitalismo em uma fase decrescente, depois de percorrer a longa trajetória expansionista que havia se iniciado após o fim da Segunda Guerra Mundial. Efetivamente, o fim daquela onda longa de prosperidade é confirmado com uma inflexão da taxa geral de lucro e, consequentemente, seguida de um desempenho econômico assinalado por estagnação, desemprego e inflação em níveis elevados. Contudo, depois de penar por um período de mais de uma década de estagnação, abrese um processo de retomada, ainda que de forma limitada, em meados dos anos 1980, de uma trajetória ascendente e de crescimento da acumulação, conforme pode ser verificada no Gráfico 1, a seguir. (Dumènil; Lévy, 2004, 2007).

O gráfico permite afirmar que os grandes centros dominantes do capital, constituídos por países da Europa e dos EUA - e excetuando o Japão, têm um desempenho similar durante os anos que compõem o final da década dos 1970 e 
Gráfico 1 - Taxa de lucros (\%): EUA e Europa (economia privada)

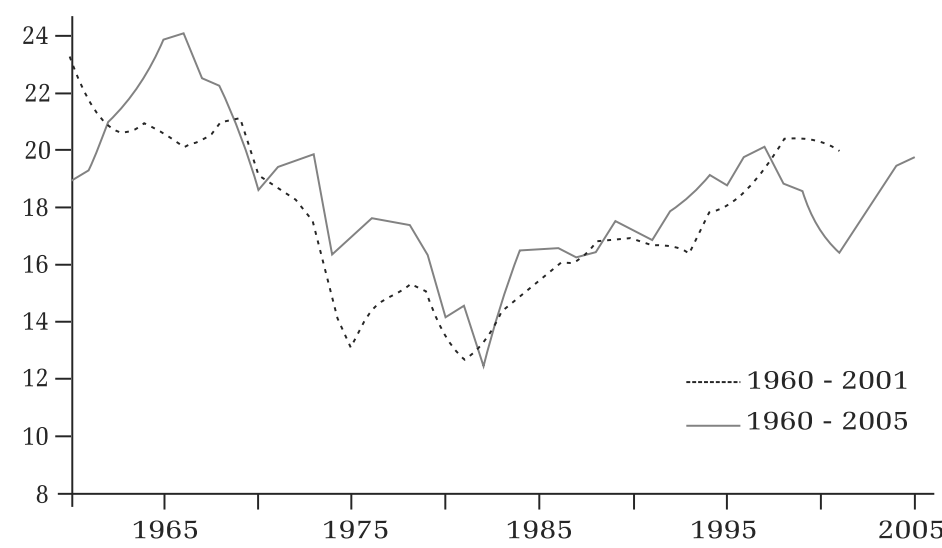

Estados Unidos — Europa ---- das relações capitalistas.

No entanto, esse quadro contraditório, ao tempo em que acentuava a instalação de uma rota de fuga da estagnação, introduzia um conjunto notável de transformações logicamente coerentes à ancoragem da plataforma necessária ao relançamento de um novo ciclo robusto de acumulação. Assim, no que tange às transformações verificadas nas últimas décadas, podemos destacar, entre outros resultados, a universalização das relações capitalistas em escala planetária, acompanhada do fim do pré-capitalismo e a aber- os que compõem o início da década dos 1980 , quando apresentam as menores de taxa de lucro. É possível observar-se, também, que a elevação ocorrida a partir de 1983 segue com inflexões, mas sem jamais alcançar os níveis anteriores a 1965 e 1966. Esta tentativa de superação da situação denominada, principalmente pela economia política burguesa, particularmente nos EUA, de "estagflação", significaria a abertura de uma nova fase de desenvolvimento na história do capitalismo, a princípio, saudada como portadora de um desígnio inequivocamente virtuoso, e que passaria a ser chamada de globalização, ou de mundialização da economia.

Mas, a bem da verdade, pode ser afirmado que a experiência de solução da crise surgida nos anos 1970, por intermédio de mecanismos e instrumentos inscritos no modelo do neoliberalismo e da globalização, inaugurou uma trajetória errática da acumulação de capitais, marcada por turbulência e vulnerabilidade sistêmicas. Tal movimento foi assinalado por um intenso processo de inovações nos planos produtivo, financeiro e deslocamentos geográficos, cujas implicações mais expressivas se exprimiram mediante a integração categórica de amplas áreas do planeta ao mercado mundial e à reprodução capitalista sistêmica, ensejando, efetivamente, a constatação de uma verdadeira globalização (mundialização) tura de novos espaços (amplitudes espaciais, ramos produtivos e mecanismos de desregulamentação) apropriados para a extração da mais-valia.

Nesse sentido, destaca-se, particularmente, a inaudita efetivação de um exército industrial de reserva em escala mundial (Chesnais, 2006) e a iniciação, e o desdobramento de um novo paradigma tecnológico seguramente promotor da desvalorização da força de trabalho (Balanco, 2008). Em verdade, o conceito de Exército Industrial de Reserva, ou superpopulação relativa, cunhado por Marx para a realidade que ele vivia na Inglaterra em meados do século XIX, deve ser utilizado hoje de forma adaptada ao fenômeno real. Quando se observa que, atualmente, em um país como a Espanha, 25\% da população economicamente ativa se acha desempregada, devese concluir que, de fato, não se trata de desemprego provocado por uma recessão conjuntural e, portanto, teoricamente superável, mas sim, de uma parcela da população apta a participar do mercado de trabalho e que jamais será incluída no sistema produtivo. É certo que o capital, em suas diversas frações, poderá resgatar um percentual deste novo "exército de reserva", substituindo os mortos, os mutilados ou os “inadaptados" de toda sorte. É verdade, também, que o referido "exército" continua agindo como nos tempos de Marx, pressionando para baixo a 
remuneração média dos trabalhadores da ativa. Contudo, é importante assinalar que, para a construção de uma teoria geral da crise hoje, restringir a observação do fenômeno a esses elementos significa perder para o acessório aquilo que é o mais significativo: os desempregados, junto à massa crescente dos excluídos na Europa, nos EUA e no mundo dão a substância de um fenômeno muito mais significativo para a conjuntura atual, que é aquele da destruição massiva de forças produtivas vivas. Ele constitui um dos traços maiores da atual fase do capitalismo. Tal fenômeno expressa, de modo quantitativo e qualitativo, também, um limite social instransponível para o capital (Nóvoa, 1993). Isto nos remete àquela famosa passagem da Contribuição à crítica da economia política, na qual Marx se refere aos bloqueios que as forças produtivas sociais passam a sofrer a partir de um determinado momento e ao fato de que se abre, a partir de então, um período mais ou menos longo de transformações sociais. Tais transformações tanto podem levar à superação dos impasses de modo positivo, como à barbárie.

\section{HIPERTROFIA DO CAPITAL FINANCEIRO}

Em meio a essa complexa experimentação, uma das transformações mais relevantes que o capitalismo internacional faz surgir após o aparecimento da crise dos anos 1970 diz respeito à reconstrução, em novas bases, da esfera financeira. Expressando fundamentalmente as dificuldades localizadas no processo da acumulação de capi$\mathrm{tal}$, as finanças adquirem um grau de autonomia inédito frente à esfera produtiva, descolamento que alguns autores nomeiam de nova "hegemonia das finanças" (Dumènil; Lévy, 2004) ou de “mundialização financeira” (Chesnais, 1998). Seguramente, a financeirização representa, alternativamente à esfera produtiva, um mecanismo de busca da lucratividade para o capital nos termos a que já nos referimos. Não um mecanismo secundário. Ao contrário, ele se transforma em regularidade dominante, em virtude das dificuldades de fuga à ação da lei da queda tendencial da taxa geral de lucro. A macroestrutura financeira da globalização é formatada de maneira a viabilizar o movimento do capital-dinheiro em busca da liquidez absoluta, representando a geração de juros e outras formas de renda decorrentes de transações com ativos financeiros. A lógica dessa forma de capital, neste contexto, é a de potencializar a rentabilidade por meio de um conjunto de ativos, agentes e instituições financeiras que atuam de maneira muito distinta das tradicionais instituições financeiras, particularmente os estabelecimentos bancários. É como diz Gill: “o aumento do tamanho dos bancos não é senão um aspecto do formidável crescimento do setor financeiro em geral no curso dos anos recentes (...)" (Gill, 2012, p. 108). Se, em 1970, o Goldman Sachs tinha 1300 empregados e o Morgan Stanley 3500, em 2008 o primeiro já tinha 30 mil e o segundo 55 mil. Nos EUA, a dívida do setor privado em percentual do PIB dobrou entre 2000 e 2007, mas, tendo dobrado entre as famílias e ficado estável no setor não financeiro, foi multiplicada por 15 no setor financeiro. Em 2007, a capitalização em bolsa de valores em todo o mundo representava 1,2 vez o montante do Produto Mundial Bruto (PMB), de 55 trilhões de dólares. Conforme pode ser verificado no Gráfico 2, o montante total de capitalização em bolsa, assim como em títulos da dívida privada, dívida pública e ativos bancários, representava 4,4 vezes o PMB, distribuídos da seguinte maneira: capitalização da bolsa 65,106 trilhões, títulos da dívida pública, 28,629 trilhões, títulos da dívida privada, 51,586 trilhões, ativos bancários, 95,768 trilhões (Gill, 2012, p. 109).

Constata-se, agora, uma nova institucionalidade, reunindo corporações financeiras, grandes conglomerados produtores de mercadorias e serviços, governos e agentes negociadores de papéis das mais diferentes modalidades. A remuneração ao capital-dinheiro no âmbito dessa estrutura põe em relevo seu caráter especulativo e predador e a intensa presença do capital fictício, já que visa à captura da mais-valia apoiada em 
Gráfico 2 - Valor global dos ativos financeiros e o PIB mundial (em US\$ trilhões)

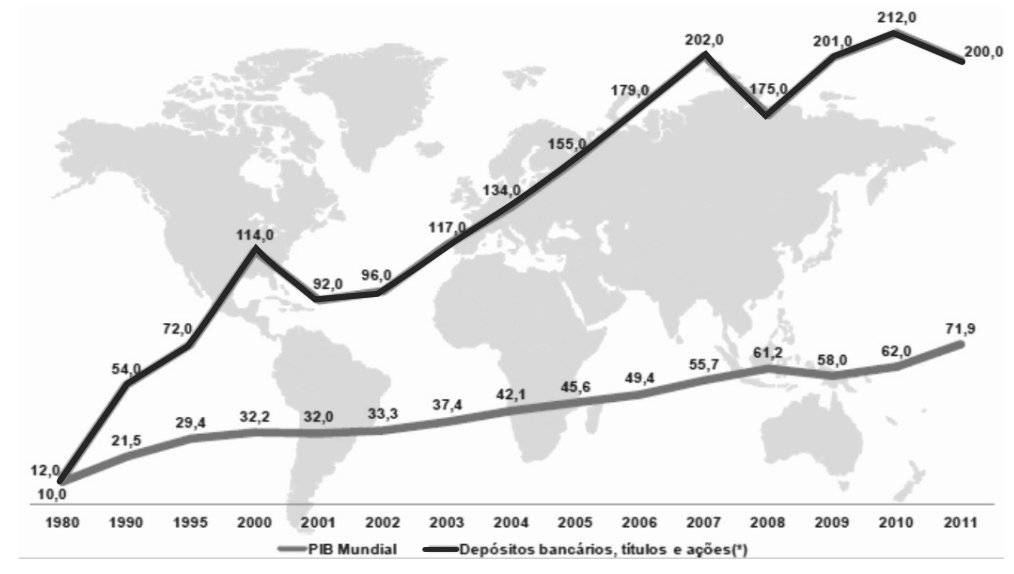

(*) Não estão incluídos aplicações financeiras na forma de derivativos, swaps, garantias etc.) Fonte: Lacerda, 2012

riqueza previamente inexistente (Mcnally, 1999). No Gráfico 2, podemos verificar uma mostra do descompasso entre o crescimento da economia real (PIB) e o crescimento do estoque de ativos financeiros, para a economia mundial, entre 1980 e 2011. Vê-se, assim, que, a preços correntes, enquanto o PIB mundial cresceu $620 \%$, ao mesmo tempo, o estoque global de ativos financeiros, mesmo sem incluir algumas modalidades do capital especulativo atual, expandiu-se em cerca de 1570\% no período em questão.

As transformações acima assinaladas conduziram o capitalismo para um novo estágio, cuja marca mais conspícua, poderia ser afirmado, é a instabilidade e a turbulência. Se, por um lado, há um turbilhão de novos elementos produtivo-financeiro-espaciais, conformando a nova estrutura mundializada da reprodução ampliada do capital, por outro lado, essa mesma estrutura, já em pleno século XXI, se apresenta tão carregada de contradições que um desfecho favorável à sociedade burguesa parece cada vez mais improvável.

\section{LIMITES ECOLÓGICOS APROFUNDADOS PELAREPRODUÇÃO AMPLIADA DO CAPITAL}

Da afirmação precedente não se pode deduzir, automaticamente, uma hipótese otimista de substituição da realidade atual por um sistema mundial póscapitalista, pois, além da destruição permanente, operada a partir do capital fictício, do trabalho morto e das forças produtivas vivas, a improbabilidade de um desfecho de acordo com a lógica capitalista, além da realidade que acabamos de citar, diz respeito, também, aos limites ecológicos provocados pela destruição perpetrada à natureza pela compulsão (quase automática, se não estivéssemos tratando de uma realidade "dirigida" e organizada, em muitas medidas, pelos donos do poder no planeta) em buscar lucro. A reprodução ampliada do capital impõe destruição ao meio ambiente e, em muitos casos, é impossível a restauração das condições naturais anteriores. O esgotamento de fontes energéticas fósseis, que vem sendo promovido há mais de um século, é simplesmente absurdo do ponto de vista da sobrevivência do próprio sistema! Observe-se que os EUA já alcançaram o topo máximo possível de sua extração de petróleo. Eles continuarão a explorá-lo, mas, cada vez mais, em níveis inferiores aos que já alcançaram, o que só faz acirrar suas contradições, particularmente as geopolíticas, que colocam suas relações com o Oriente Médio no fio da navalha. Ora, se o capital não se reproduz ampliadamente sem utilizar o trabalho vivo e morto, também lhe é impossível não utilizar matérias brutas, ou seja, a forma mais direta através da qual a natureza alimenta os ciclos produtivos diversos. Só para ficarmos no Brasil e nos ecossistemas menores, em menos de trinta anos, dizem os especialistas, a caatinga, e mesmo o cerrado, estarão irremediavelmente mortos. E o que dizer dos diversos sistemas da Amazônia que não conseguem encontrar defesa contra a sanha avassaladora do comércio internacional de madeira, da criação de gado, assim como aquele do planalto central do Brasil nos quais já se vive 
um processo de mudança climática real, com a elevação das temperaturas e a redução drástica do acesso à água dos rios que estão secando?

Dessa maneira, um dos desdobramentos mais notáveis decorrentes dessas transformações está vinculado à integração mais completa dos países periféricos à nova estrutura reprodutiva. Em particular, do ponto de vista espacial, algumas regiões, que, durante quase todo o século $\mathrm{XX}$, se mantiveram pouco integradas, ou insuficientemente articuladas com a economia capitalista mundial, foram inapelavelmente acopladas a esse mecanismo reprodutivo. Consideremos, portanto, alguns países de grande extensão territorial e população elevada, como é o caso dos chamados BRICs (Brasil, Rússia, Índia e China), também metafórica e ideologicamente denominados de países "emergentes". A visão econômica conservadora assinala que o "desenvolvimento" recente, experimentado por esses países, representa a prova cabal da capacidade de o modelo de sociedade liberal-mercantil (diga-se, capitalista) integrar, virtuosamente, regiões do planeta antes consideradas excluídas das benesses experimentadas até então somente pelos países desenvolvidos. Mas, parece pouco provável que esta tese encontre respaldo na verdade dos fatos e nos fundamentos das leis de movimento e reprodução do capitalismo. Seria muito mais plausível reconhecer que uma trajetória anunciada na gênese do capitalismo agora se manifesta mediante a universalização das relações capitalistas com a integração de novas regiões ao Mercado Mundial, e a supressão das relações pré-capitalistas.

\section{ELEMENTOS ESTRUTURAIS DA CRISE ATUAL}

A versão conjuntural mais recente da crise econômica do capitalismo recebeu a denominação de crise subprime. O que é o subprime? Trata-se de "um neologismo estadunidense, como bem explica Gill, que quer designar hipotecas com risco elevado que se colocaram no centro da crise imobiliária americana caracterizando o fato de que elas se encontram abaixo dos níveis estabelecidos de solvabilidade exigidos pelo sistema bancário" (Gill, 2012, p. 168). A crise das hipotecas subpreferenciais eclodiu nas entrâncias financeiras do mercado imobiliário norte-americano, mas se alargou para o mundo, com enormes repercussões posteriormente à sua deflagração em 2007, particularmente com os colossais abalos vividos pela União Europeia, que despontaram, envolvendo as dívidas públicas (estatais) de vários dos países que a compõem. Por outro lado, também poderíamos denominar esta crise como mais uma aguda manifestação do recente e crônico fenômeno da financeirização, ou o estouro de mais uma das várias bolhas estruturais que vêm se formando desde os anos 1990.

Seria enganoso, contudo, explicar as crises financeiras que acompanham a explosão de bolhas estruturais com o recurso a variáveis exclusivamente financeiras ou institucionais como acontece com muitas avaliações, mesmo de caráter heterodoxo (Milan, 2012). A via correta de explicação, a nosso juízo, demanda a identificação da crise do subprime, não como um epifenômeno, mas como uma das muitas manifestações de um processo estrutural objetivo, que continua em pleno desenvolvimento, desde sua eclosão, em meados dos anos 1970. Esta linha de raciocínio se apoia em um recurso metodológico, qual seja a compreensão da natureza do modo de produção capitalista de mercadorias, do valor delas, da acumulação de capital mediante um grau de abstração mais elevado, o que permite situar o fenômeno aqui analisado em torno dos requisitos fundamentais denominados de condicionantes gerais da crise que, não raro, atuam como reais determinações. Expressam, portanto, traços comuns a todas as crises; são imanentes à sua essência. Remetem, portanto, à sua estrutura e à dinâmica da economia capitalista (Filgueiras, 2009). Nesse plano lógico-teórico, a crise ocupa o lugar de um fenômeno ordinário do capitalismo e, simultaneamente, constitui-se em uma categoria de análise incontornável dessa eco- 
nomia, mesmo que se nos apresente mais diretamente apenas como fenômenos da aparência (Gill, 2002; Mattick, 1974; Marx, 1986; Shaikh, 2006).

Ampliando os desenvolvimentos preliminares a respeito da noção de crise já antecipados, podemos afirmar que o fator estrutural que conduz à crise geral é a insuficiente valorização do capital, conquanto a acumulação esteja sujeita a limites e, portanto, a interrupções. Mas, tal constatação nada mais é do que a expressão material do efeito contundente da lei da tendência à queda da taxa geral de lucro, a mais importante das leis econômicas do capitalismo deduzidas por Marx (1986). No enunciado de Marx e na realidade mesma, sua ação é diferenciada em função das frações e dos setores do capital. De acordo com esta lei, a acumulação, ao atingir determinados limites, se depara com uma insuficiente massa de mais-valia para valorizar certo montante de capital acumulado. Em síntese, trata-se de uma dinâmica que, endogenamente, encerra potenciais irrupções concretas de insuficiência relativa de lucratividade, geradoras de efeitos que devem ser enquadrados na categoria geral de crise de “sobreacumulação" (Mattick, 1974).

Ao mesmo tempo em que a crise corresponde a um fenômeno inevitável, ela também representa um evento indispensável, em função de seu papel de limpeza, de destruição de valores e de restabelecimento das condições necessárias à retomada dos processos "normais" da acumulação. Entretanto, nota bene, a baixa remuneração que os capitais produtivos encontram hoje para se reproduzirem ampliadamente, a partir desses setores, não quer significar que a crise atual seja uma crise de escassez de capitais. Ao contrário, os limites dos investimentos produtivos e os limites do mercado consumidor terminam promovendo um excesso de capitais que precisam realizar mágicas para conseguir remuneração apropriada ou, dito de outro modo, Fonte: Chesnais 2012, p.51 uma lucratividade crescentemente aumentada ou, então, falir. Tal situação poderá ser deduzida, por exemplo, do fenômeno constituído pelo crescimento dos ativos financeiros globais em relação ao crescimento do PIB mundial no período 1980-2006, ilustrado pelo Gráfico 3, a qual, embora semelhante à anterior, permite uma melhor visualização da modificação da proporção dos estoques de ativos financeiros relativamente à magnitude do PIB mundial.

É, pois, um processo logicamente estruturado a partir da lei do valor e da produção mercantil sob o comando do capital em geral. Acontece que, no estágio atual de "desenvolvimento" do capitalismo, é o capital financeiro que expressa a fusão das frações dominantes dos capitais industriais, agrícolas, comerciais e bancários, e que orienta e submete a lucratividade dos capitais como um todo. Em sua essência, ele traz todos os capitais, embora se distinga de todos. Ele não pode, por razões estruturais e relativas à lógica de sua reprodução - e dos capitais em geral, se achar blindado às crises. Em sua configuração completa, o processo de valorização do capital incorpora a presença da categoria dinheiro, que representa a forma mais geral da riqueza, apresentando, por isso, a possibilidade do surgimento Gráfico 3 - Ativos financeiros globais em porcentagem do PIB mundial

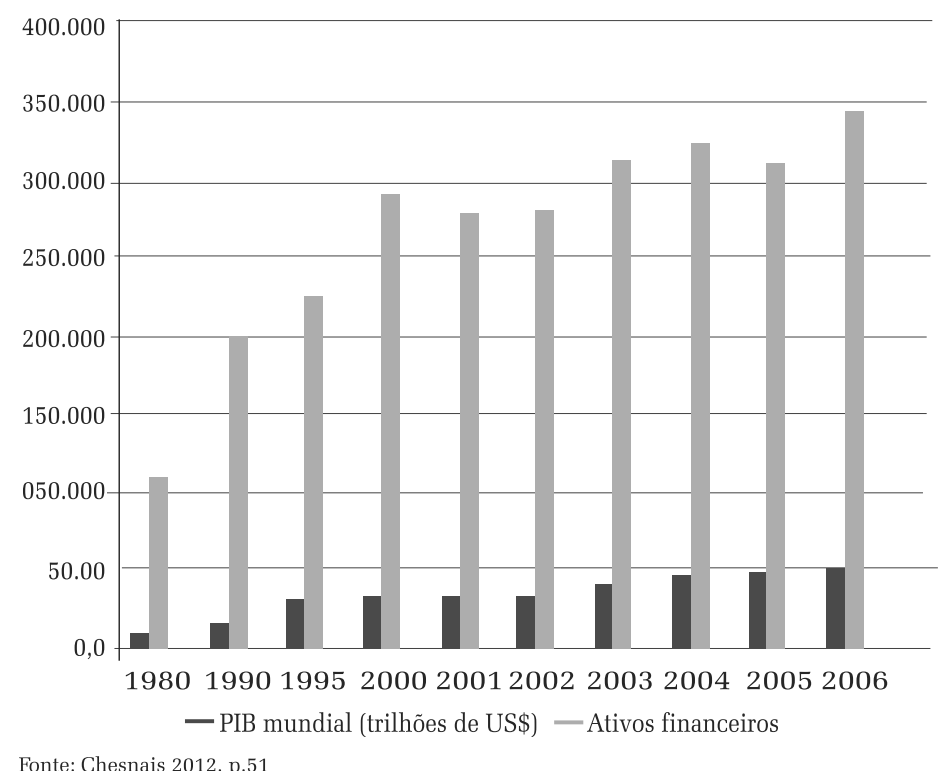


de dificuldades quando da passagem do valor da forma mercadoria para a forma dinheiro no âmbito do circuito do capital (conservação e aumento do valor $\rightarrow$ D-M-D'). Ao mesmo tempo, este movimento de valorização, por se manifestar de forma aparente, ou fenomênica, como lucro (ou juros), no plano da circulação, tendo em vista a existência do crédito e do capital de empréstimo, cria a ilusão da extração de mais valor do dinheiro em si mesmo (D - D'). Evidentemente, em termos práticos, semelhante resultado equivaleria à desnecessidade da atividade produtora de mercadorias, o que contrariaria totalmente - e contraditoriamente, a lei do valor, a qual demonstra que a produção de mais-valor somente ocorre em atividades diretamente produtivas, portanto, nos setores industriais e agrícolas.

A negação da esfera da produção aparece como a base sobre a qual emerge o "capital fictício" e introduz a probabilidade de autonomização das finanças. No entanto, mais uma vez, tratase de um processo contraditório. Se o ideal do capital financeiro é o "desprezo" total e absoluto pelos processos produtivos - e mesmo pela comercialização de mercadorias, ele também se origina nos referidos setores, sem conseguir, por isso, se emancipar realmente dos mesmos. Suas múltiplas naturezas são mais que ambiguidades. Sua independência aparente perdura durante certo tempo em função de seu ciclo particular de lucratividade bem mais curto que o dos outros capitais. Mas, em decorrência de seus vínculos com as demais formas concretas do capital, ao esbarrar com as crises dos setores produtivos e comerciais, o capital financeiro também acaba por transmitir àquele as consequências de seus colapsos. Trata-se, pois, de uma simbiose explosiva. Por conseguinte, a dominação do capital financeiro, que se acha, por sua vez, dominado pelo fetiche do lucro imediato, é dependente da produção de mercadorias e das contradições imanentes da extração da mais-valia e de sua repartição entre as frações do capital no processo permanente e infinito da busca pela valorização do capital como motor da acumulação.
É esse processo que faz Chesnais reafirmar a tese de que há, na atualidade, um intenso processo de centralização e concentração do capital e uma intensificação da concorrência intercapitalista. A crise começada em agosto de 2007 ocorre ao final de uma longa fase de mais de cinquenta anos de acumulação quase ininterrupta - a mais longa de toda história do capitalismo, na qual os governos capitalistas do mundo souberam se utilizar de formas de cooperação, tácitas ou explícitas, decorrentes das políticas aplicadas pelas burocracias na URSS e na China, para impedir toda e qualquer revolução anticapitalista, anti-imperialista e antiburocrática, desde Berlim em 1953 a Tiananmen em 1989. Os governos dos principais países capitalistas "em suas relações mutáveis com os centros privados de centralização do capital e de poder da finança e da grande indústria”, a partir de 197880, puderam contornar assim suas contradições. Quando do fim dos “Trintas gloriosos", teve início a recessão. O que permitiu, pois, o longo período de acumulação de capital - além das determinações da política, foi a gigantesca destruição de capital produtivo, dos meios de transporte, de comunicação, a morte e a inutilização de mais de 100 milhões de indivíduos, além da destruição dos valores cristalizados em casas, edifícios, portos, aeroportos como resultado da maior operação destrutiva desenvolvida pela humanidade na Segunda Guerra Mundial, se quisermos esquecer a destruição provocada já pela Primeira Guerra e pela crise de 1929/30. O fim da URSS coroou a afirmação, portanto, do neoliberalismo global, abrindo espaço, não somente político, mas econômico, para o júbilo dos capitalistas do planeta, particularmente dos que compõem - anonimamente (ou não), o clube seleto do capital financeiro.

Por conseguinte, a dimensão financeira do capitalismo contemporâneo se estrutura mediante mecanismos e canais extremamente flexíveis e abrangentes no tempo e no espaço, chegando mesmo, em determinadas circunstâncias, a negar a existência formal do Estado-nação, já que os capitais financeiros exigem liberdade absoluta de movimento em uma perspectiva 
supranacional. Não por acaso, os volumes de riqueza, na forma fictícia, que circulam diariamente mundo afora, superam, muitas vezes, a riqueza real produzida pelas esferas produtivas como procuramos ilustrar pelos dois gráficos imediatamente anteriores. Mas, como predomina a lógica da valorização do capital fictício tão somente no domínio financeiro, a economia como um todo, assim como a vida e o destino dos povos, acabam conduzidos por essa diretriz inexorável.

Nesse sentido, podemos verificar dois aspectos importantes em relação aos quais alguns autores parecem corroborar. De acordo com Lapavitsas (2009b), em primeiro lugar, a financeirização aprofundou a complexidade do "imperialismo", dado que países considerados subdesenvolvidos têm sido forçados a manter grandes reservas em divisas estrangeiras, as quais são transformadas em empréstimos dos países pobres para os países ricos. Dessa maneira, o capital privado produz um grande montante de retornos elevados, enquanto, ao mesmo tempo, tais "empréstimos" não produzem os mesmos ganhos elevados para os países subdesenvolvidos, ao contrário, salvo para as frações do capital "nacional", que foi capaz de se integrar ao capital financeiro internacional e que, por conseguinte, submete seu critério à lógica da lucratividade de sua nova fração dominante internacional. Tais fluxos de capital, acentuadamente anárquicos, têm beneficiado, sobretudo, os EUA, que detêm o monopólio da emissão da moeda internacional, o dólar, mas que, simultaneamente, estão na origem da formação da bolha estrutural nos EUA no período 2001-2007. Em segundo lugar, a financeirização tem introduzido hábitos morais que penetram na vida social e individual, já que o conceito de "risco" torna-se banalizado em torno das práticas financeiras e se disseminam para todo o tecido social mundial. Decorre daí a busca ambiciosa - por altos padrões de vida e de rendimentos, que, na maioria dos casos, não conseguem acompanhar as aspirações subjetivas de seus portadores - que transforma empréstimos para aquisição de resi- dências e a contribuição para fundos de pensão em "investimentos" privilegiados pela especulação e pelo parasitismo do capital financeiro, carreando os indivíduos comuns para o interior das bolhas financeiras.

Em razão disso tudo, a manifestação assombrosa desse fenômeno no capitalismo contemporâneo, a financeirização, denota a persistência da crise estrutural enfrentada por essa economia, desde os anos 1970, mediante desdobramentos históricos e conjunturais particulares.

\section{PARTICULARIDADES DA CRISE SUBPRIME: efeitos sobre o Brasil}

Não é possível compreender a última crise "conjuntural" da economia capitalista internacional, deflagrada em 2007 e ainda em propagação, sem considerá-la uma componente da crise sistêmica geral. O seu presente se acha enraizado, como vimos, no processo de longa duração, cujas origens remetem aos anos de 1970, quando do crepúsculo da longa onda de crescimento do pós-Segunda Guerra. Sua inteligibilidade só pode, realmente, ser alcançada se lançarmos mão das seguintes considerações: 1) a crise atual representa a superposição entre a crise geral e os determinantes históricos ocorridos nas três últimas décadas; 2) as crises do subprime e das dívidas estatais denotam a interação entre o enfraquecimento da acumulação e a reconstrução da esfera financeira em moldes inéditos e 3) esta crise espelha o declínio da vitalidade das economias avançadas e a inclusão de novos eixos sistêmico-geográficos à reprodução ampliada do capital no âmbito do mercado mundial (Brenner, 2009, Balanco, 2010).

Como expressão das dificuldades enfrentadas pelos países desenvolvidos em prosseguir com a acumulação de capital em condições de saciedade lucrativa, a nova estrutura financeira foi desenvolvida em articulação com as mudanças produtivas e aquelas correspondentes aos novos eixos geográficos de acumulação. Forma- 
se, assim, um processo sistêmico, em escala mundial, cuja marca distintiva é a introdução de uma hiperflexibilidade de deslocamentos e conversão do capital das formas reais (forma mercadoria) para as formas nominais (forma dinheiro), e vice-versa, efetivando um movimento centralizado dos excedentes gerados nos mais distintos países e setores da economia. Contudo, em última instância, o capital financeiro atua como a referência principal, ou como norma regular para a fixação dos parâmetros de rentabilidade do capital em todas as suas formas concretas (capital industrial, agrário, comercial e bancário). A fusão que forma a categoria capital financeiro constitui uma unidade de contrários estruturada hierarquicamente. Explica-se, assim, o surgimento dos recorrentes ciclos financeiros curtos e das bolhas estruturais, que, ao explodirem, resultam nas graves crises financeiras presenciadas na contemporaneidade e, entre elas, a crise atual (Panitch; Gindin, 2009).

As duas mais importantes recentes bolhas financeiras são exemplos desse fenômeno. A primeira ocorreu na última metade dos anos 1990, a bolha da "nova economia", alavancada por um processo de financiamento apoiado nas bolsas de valores para o fomento de empresas de novas tecnologias das comunicações e internet, as chamadas empresas "ponto com", cujos valores patrimoniais, calculados em preços das ações, cresciam estratosfericamente da noite para o dia. E, a segunda, a bolha subprime, cujo colapso ainda provoca efeitos devastadores. Esta última foi a impulsionadora de um ciclo curto de recuperação da economia estadunidense entre 2001 e 2007, apoiada em uma gigantesca onda de financiamento ao consumo familiar, a partir do mercado de hipotecas, mas, de fato, alavancado por capitais transferidos de países emergentes mediante os dispositivos da dívida pública americana e da aquisição dos referidos títulos em particular pela China.

Se a acumulação em geral passa a ser norteada pela rentabilidade do capital financeiro, então, a relação entre o capital fictício, as novas ten- dências de crescimento e a bolha financeira passa a ter uma ascendência determinante sobre o processo da reprodução do capital no conjunto do sistema mundial. Dito de outra forma, desde que os encadeamentos do circuito econômico global e a formação da demanda foram reconfigurados para transitarem pela esfera financeira, não pode mais haver um "regime de crescimento" sem o fenômeno da bolha, sem a formação de um capital fictício sem precedente. Mas a bolha não pode assegurar maisvalia financeira aos investidores sem a condição de ser alimentada permanentemente. É aqui que intervêm os fluxos financeiros externos dos quais os Estados Unidos são os principais beneficiários (Chesnais, 2001, p. 66).

Cada um desses ciclos ocorre sob a guarda de uma bolha estrutural característica, relativa à precedente, e carrega singularidades próprias que se expressam, sobretudo, por meio de "inovações" financeiras. Nesse sentido, a crise subprime vincula-se ao desenvolvimento de um sistema bancário distintivo, implantado mediante a extensão de empréstimos para setores historicamente oprimidos da população em decorrência da mercantilização de vários campos produtores e ofertantes de bens e serviços públicos consumidos pelos segmentos assalariados. A captura desses espaços pelo capital acarretou a expansão da oferta privada de meios educacionais, residenciais, serviços de saúde e planos de aposentadoria, o que acabou por exigir o recurso forçado dos assalariados ao sistema bancário (Chesnais, 2012; Lapavitsas, 2009a). Basta lembrar que será a partir dos anos 1970 que os assalariados do planeta passaram a receber seus salários em contas bancárias, o que constitui um volume de capitais gigantesco para o setor bancário, do capital financeiro que se transforma num agente captador para este último. A partir de então, além das poupanças que preexistiam, os bancos passaram a criar, cada vez mais, novos serviços a serem vendidos aos clientes. Estes, em muitos casos, não são sequer conscientes das "transações" que os bancos lhes impõem e fazem por eles. Tudo isso sem falar no volume de recursos provenientes dos sistemas da 
seguridade social, que são liquefeitos instantaneamente em capitais, ao serem depositados mensalmente na conta correspondente a cada trabalhador dos diversos setores. Desse modo, rendas, salários, poupanças, etc. viram capital tão logo chegam às contas dos clientes de um banco.

Essas “inovações” expressam a presença de alguns elementos cruciais, componentes deste processo, até o momento pressupostos, e que devem, portanto, agora ser postos às claras. Entre as muitas transformações que o capitalismo internacional colocou em prática encontram-se amplas medidas de integração, desregulamentação e flexibilização. Essa verdadeira avalanche, conhecida por neoliberalismo, pressupõe que o capital deve passar a desfrutar de acesso amplo a todos os setores, inclusive aos serviços públicos, além da propriedade de ativos e controle das receitas tributárias estatais como canais privilegiados de recuperação da lucratividade. Dessa maneira, os países ditos emergentes e os dominados, na divisão internacional do trabalho, foram tragados por uma onda de privatizações, à qual o Brasil compareceu com uma contribuição relevante. Neste contexto, simultaneamente, o aprofundamento da integração brasileira aos fluxos do comércio internacional colocou em marcha um amplo mecanismo de flexibilização das normas regulatórias, tanto no que tange aos vínculos econômicos externos como no que concerne às relações do mercado interno de trabalho.

Este é o cenário em que a crise geral de superprodução do capitalismo internacional, juntamente com as transformações dela emanadas, entre elas a inaudita financeirização, permanece em continuidade no interior da economia mundial até os dias que correm. Sob o neoliberalismo e seus copiosos volumes de excesso de liquidez e fontes permanentes de crise no curto-prazo, capitais financeiros especulativos estritamen- Fonte: Gonçalves. 2012 te fictícios ou capitais na forma de Investimentos Externos Diretos (IED) vagueiam pelo mundo com o propósito de efetuar punções nas riquezas das diferentes nações. Como efeitos de grande envergadura, podemos citar a mudança de propriedade dos meios de produção entre nacionais e estrangeiros, e a apropriação de parte da receita estatal, diga-se da mais-valia social, mediante o mecanismo das dívidas públicas, o que gera reordenamentos de monta nas composições e acordos entre as diferentes frações das classes dominantes, que se interpenetram no plano nacional e internacional. Podemos dizer que nos encontramos, agora, em um novo estágio das "exportações de capital", implementado sob a cobertura de mecanismos cruéis de ataques às condições materiais de vida dos trabalhadores e dos povos.

No caso brasileiro, destaca-se a introdução de uma vulnerabilidade decorrente da dependência ante os fluxos de capitais especulativos, a entrada de IED e as receitas de exportação, conforme podemos verificar, parcialmente, no Gráfico 4.

Estudos efetuados por Reinaldo Gonçalves mostram que a acumulação de capital no Brasil, através do IED, tem consequências importantes na geração da renda interna. O autor chega à conclusão, conforme mostrado no Gráfico 4, que as empresas estrangeiras elevaram sua contribuição direta para a geração do valor da produção (PIB) de 8,6\%, em 1995, para 14,7\% em 2005 (Golçalves,
Gráfico 4 - Brasil: Investimento Externo Direto (IED), formação bruta de capital fixo (FBCF) e participação das empresas estrangeiras no PIB (ETs) $(1995-2005)(\%)$

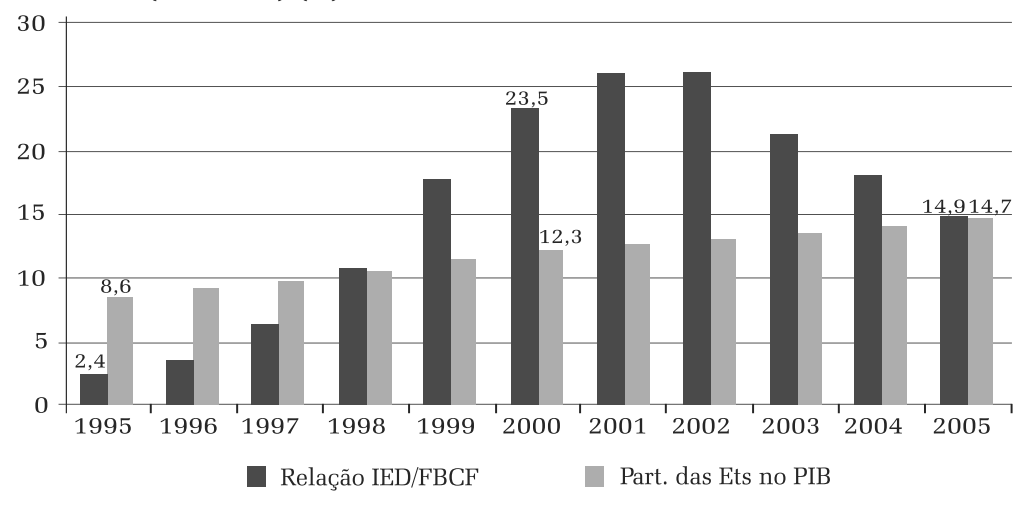


2011, pág. 15).

Observa-se, também, que a participação do IED na formação interna de capital, dá o tom da internacionalização da economia brasileira, posto que a continuada e expressiva expansão da relação IED/FBCF no período 1995-2002 está em plena sintonia com o processo de privatização levado a efeito, pelo menos, nos dois mandatos de FHC, mas não só (Golçalves, 2002, pág. 16). Ao mesmo tempo, os dados informam quão mais dependente do capital externo se tornou a economia brasileira, para efetivar taxas de crescimento minimamente representativas. Acrescente-se, por outro lado, no âmbito da vulnerabilidade da economia brasileira frente à economia mundial, a excessiva importância adquirida, nos anos recentes, pelos bens primários de exportações, que experimentaram um espetacular incremento de demanda oriunda de alguns países emergentes, particularmente a China. Dessa maneira, nossa economia, depois do aprofundamento de sua integração, nos moldes descritos, à economia mundial, a partir do início dos anos 1990, passou a ter sua dinâmica interna fortemente correlacionada aos movimentos da economia internacional (Letízia, 2012).

\section{À GUISA DE CONCLUSÃO: o último estágio do capital}

A portentosa onda de transformações, ocorrida no âmbito da economia capitalista mundial nos últimos decênios, mostrou-se, antes de tudo, como de caráter contratendencial, visando a contenção do amplo processo de crise estrutural surgido em decorrência do esgotamento da onda longa de crescimento do pós-Segunda Guerra. Assim, contraditoriamente, ao tempo em que as mudanças introduzidas se revelaram poderosas alavancas inovadoras nos planos produtivos e financeiros, também se mostraram portadoras de profundos conteúdos regressivos. São medidas que, mesmo transformando, acentuadamente, o capitalismo, não conseguem viabilizar uma nova base sólida para a recuperação da acumulação em subs- tituição àquela erodida no início dos anos 1970 .

Com isso, poder-se-ia afirmar que o novo modelo de reprodução do capitalismo no tempo presente tem limites visíveis e que, contraditoriamente, potencializa o prolongamento de uma crise orgânica, que se desdobra em regressões ameaçadoras aos destinos da humanidade.

Se nos EUA e na Europa sobressai o avanço destrutivo sobre as receitas estatais via a dívida pública, em países considerados emergentes - mas também nos denominados subdesenvolvidos - observa-se o acúmulo de reservas nos bancos centrais e estatais que terminam, assim, bombeando e retirando da circulação recursos necessários às inversões produtivas e às políticas públicas. Tais reservas são, por mecanismos diversos, drenadas pelo capital financeiro internacional. O endividamento dos estados da União Europeia, particularmente dos mais frágeis - mas cujas populações estão hoje submetidas a duras diretrizes recessivas e estagnantes (Chesnais, 2012 e 2007), o que as têm obrigado a reações massivas e carregadas de unidade política geral jamais vistas na história - tem essa função.

As regiões do planeta, submetidas secularmente aos centros capitalistas, têm se deparado, nas décadas recentes, com profundas mudanças, as quais refletem as intensas modificações da estrutura reprodutiva do capitalismo na esfera internacional. O Brasil pode ser considerado um dos espaços nacionais mais afetados por essas mudanças. Alguns autores procuram analisar os efeitos decorrentes, de um lado, da nova forma de integração brasileira ao mercado mundial, enfatizando, entre outros aspectos, a constituição de uma posição de vulnerabilidade econômica vis- $a$-vis as suas relações externas e, de outro lado, do reordenamento, nos anos recentes, na composição da propriedade do capital entre frações das burguesias nacional e estrangeira. Parte desses estudos é efetuada já de acordo com um recorte cronológico, no interior do qual está presente, como evento irradiador, a crise capitalista, atualmente em desenvolvimento e deflagrada após o colapso do mercado das hipo- 
tecas subpreferenciais da economia americana.

Os países da América Latina, como é o caso da Argentina e do Brasil, mas também muitos de outros continentes se vêm pressionados pelo que passou a ser uma exigência dos diversos organismos internacionais, que regulam o comércio e as relações financeiras mundiais, para que suas instituições bancárias estatais, seus Bancos Centrais, acumulem gigantescos montantes em moedas e divisas como reservas. Estas, em última análise além de drenarem recursos financeiros passíveis de serem produtivos, inviabilizando, assim, uma industrialização capaz de dotar tais países de independência das pressões internacionais, como as da OMC (Organização Mundial do Comércio), criam outra forma de subordinação, baseada nessa nova característica das relações internacionais de submissão ao capital financeiro internacional. Se perdurarem essas bases relacionais, toda veleidade industrialista morre com seus agentes socioeconômicos nacionais. Na verdade, o que estamos vendoé um processo de desindustrialização pura e simples, ou de transferência de bases produtivas para a China, e nossos países retomando sua natureza original: aquela na qual a dominância do padrão agroexportador termina alimentando a economia das comodities. O grande capital industrial nativo - junto com o restante do grande capital nacional, tira seus dividendos de um processo internacionalizante que solapa, definitivamente, qualquer veleidade nacionalista nesse campo. Mas não existe nenhuma incoerência aí, se compreendermos que seu critério máximo é a elevação de suas lucratividades.

Para se entender tal fenômeno, ajuda muito associar à sua descrição os processos de industrialização recente na Índia e na China, e visualizarmos as formas de superexploração da classe trabalhadora integrada à cadeia produtiva mundial. Empresas de calçados instaladas na Bahia, por exemplo, fecharam suas portas recentemente por não suportarem a concorrência com a indústria de calçados dessas regiões. Porém, muitos capitalistas de vários ramos desmontam suas plantas industriais nacionais e promovem suas transferências para os espaços chineses e asiáticos diversos, espaços esses nos quais o processo de superexploração da força de trabalho apresentam vantagens comparativas imbatíveis para o princípio da lucratividade crescente. Mas é possível observar-se, também, a transmigração de trabalhadores bolivianos, paraguaios, uruguaios, equatorianos e haitianos, que ingressam no "mercado de trabalho" brasileiro, por exemplo, em condições terríveis de superexploração e opressão. Não raro é possível encontrar condições muito próximas da escravidão mascaradas por relações jurídicas formais de assalariamento. Tal movimento populacional é visível, também, para os países avançados no hemisfério norte, fenômeno que a crise tende a aguçar. Neste sentido, desde o último quartel do século XX, surgiu uma espécie de "novo desenvolvimento" em várias latitudes e longitudes, envolvendo países como o Brasil, a Argentina, o Chile, o México, a África do Sul, a Rússia e países do leste europeu, que se juntaram à China, à Índia, à Correia do Sul e à China nacionalista (Taiwan) com a finalidade precípua de alimentar o processo neoliberal de mundialização do capital.

O capital financeiro tiraniza e vampiriza as outras frações do capital incapazes de dar um salto de qualidade. Tiraniza, também, a classe trabalhadora e o conjunto das classes sociais. Ao fazêlo, impulsiona, de forma exasperada, não somente a destruição das forças produtivas humanas (trabalhadores ativos e aqueles que jamais se integrarão, verdadeiramente, ao sistema produtivo, constituindo gigantescos lumpesinatos mundiais), mas, também, a destruição da própria natureza, mãe da qual não podemos nos apartar e a qual não podemos ignorar. O próprio capital, para continuar alimentando suas pulsões através de seu próprio fetiche, o lucro ampliado crescentemente, não pode ignorar os fundamentos naturais e sociais de sua existência contraditória. Mas faz como se pudesse. Não consegue admitir que o lucro que extrai não é propriamente lucro. É sim, transferência de renda e de mais-valia. Pois bem, nunca se alcançou um patamar tão absolutamente destrutivo do meio ambiente natural e social como o alcançado 
pelo neoliberalismo globalitário, a ponto de colocar os limites sociais e históricos do capital em face de um desafio jamais realizável: sem matérias brutas e primas, e sem trabalho assalariado, não é possível a reprodução ampliada do capital e, portanto, do lucro. Desenvolvimento econômico com mais-valia social, produzida de modo declinante, coloca em causa, não apenas o capital financeiro, como, também, todas as frações do capital que dependem da realização da mercadoria. É o que nos permite concluir, também, que as discussões que enfatizam a crise como sendo de origem financeira, ou aquelas oriundas de leituras que procuram enfatizar ser ela decorrente do capital produtor de mercadorias, do valor e do trabalho, não conseguem perceber a relação orgânica entre as várias frações do capital no processo mundial de sua reprodução ampliada.

Inquestionavelmente, o sistema econômico mundial se reestruturou, embora sob outras formas, em que se localiza a dominação do capital financeiro e uma estrutura de dominação correspondente à nova conformação do capitalismo como um sistema econômico mundial e unificado. Neste novo estágio, há a consolidação de uma totalidade nova, ou de um complexo de ligações entre as nações, em todo o planeta, mediante um fluxo de conexões. Mas o velho persiste em agarrar-se ao novo. Presenciamos, pois, uma nova estrutura financeira, articulada às mudanças produtivas introduzidas ao longo das últimas décadas, e organicamente conectadas aos novos eixos de acumulação de onde partem excedentes que, por exemplo, financiam o consumo e retroalimentam a expansão da esfera financeira nos países de economia dominante e no restante do Mercado Mundial. Mas presenciamos, também, a reinvenção do modelo primário-exportador e o rebaixamento das condições de exploração da força de trabalho indo até a superexploração dela e mesmo à escravidão, sem que seja um fenômeno exclusivo do hemisfério sul. Todas as latitudes e longitudes nos informam sobre tais fenômenos.

Enfim, hegemonia e alianças estratégicas entre frações das classes dominantes, além de consentimento, dão forma, por conseguinte, a uma economia de interdependência, hierarquia, dominação e exploração, de todo modo afirmando, mais uma vez, a tendência ao desenvolvimento desigual e combinado, que rege a evolução do capitalismo ao longo de sua história e que constrói uma totalidade orgânica como unidade de contrários. É esse processo que explica, ao mesmo tempo, a relação de autonomia e independência relativa do capital financeiro em relação àqueles que se investem na produção de mercadorias e sua inevitável dependência deles.É o que explica, também, as mesclas nacionais e internacionais do capital financeiro e o que termina guindando uma fração do grande capital nacional ao "panteão" do capitalismo mundial e ao clube do capital financeiro. A antiga base de exportação de capitais dos países avançados permanece procurando inversões diversas e produtivas nos vários espaços do planeta ditos emergentes ou "subdesenvolvidos", mas sem que tais regiões sejam apenas receptoras de capitais. Elas também exportam capitais para as economias avançadas como procuramos mostrar de diversos modos.

O aprofundamento da dominação da categoria do capital financeiro sobre as demais categorias do capital solapa, contraditoriamente, as veleidades nacionais produtivistas. E é ao mesmo tempo em que - por sua voracidade obsessivo-compulsiva por lucros crescentes, provoca, internacionalmente, a produção de gigantescos exércitos de desempregados, de sem terra, de sem-teto e do empobrecimento das antigas classes médias. Se os impasses da reprodução ampliada do capital coloca a necessidade para o capital da destruição de forças produtivas e de riqueza consumada, involuntariamente, ela amplia as bases internacionais da possibilidade da luta contra o capital. Nessas condições, a integração e a adaptação da classe operária ao capitalismo neoliberal - da qual falamos na introdução, reproduzindo o jeito americano de viver, deve ter seus dias contados.

Vivemos, pois, inequivocamente, um período histórico novo, no qual as velhas sobrevi- 
vências entram em contradição com o mundo das mercadorias e das diversas frações do capital. Nele, a "associação dos produtores livres e emancipados” só poderá fundar outro sistema pós-capitalista se abolir, definitivamente, o valor de troca pela produção de riquezas e valores de uso. O capital encontrou sua expressão última no capital financeiro e na ampliação do trabalho abstrato, fruto do incremento da produtividade que reproduz, ampliadamente, as contradições do sistema mundial, não apenas de mercadorias, mas de um capital fictício, que se distancia estratosfericamente da sua base real. Os dois polos da mesma unidade se liquefazem e se volatilizam. Eles só poderão explodir uma unidade que não é mais possível de ser contida na bolha construída pelo capital e pelo trabalho, tamanho o gigantismo de seus processos destrutivos. A crise é mundial e só será superada por um novo paradigma social mundializado, e depois de se encontrar o tempo para responder à crise ecológica, também planetária.

Recebido para publicação em 10 de fevereiro de 2013 Aceito em 09 de abril de 2013

\section{REFERÊNCIAS}

BALANCO, Paulo. A crise capitalista subprime: origens e possíveis desdobramentos. Revista Bahia Análise \& Dados. Salvador, v. 20, n. 1, p. 65-74, abril-junho de 2010.

. A dialética da globalização e a supressão do précapitalismo. Revista de Economia. Curitiba: Editora UFPR, v. 34, p. 183-203, 2008. Número especial.

; PINTO, Eduardo Costa. Padrões de desenvolvimento, funções estatais e endividamento no capitalismo contemporâneo. Análise Econômica. Porto Alegre: UFRGS, v. 23, n. 44, p. 165-188, set. 2005.

BRENNER, Robert. A crise que se aprofunda. Margem Esquerda. São Paulo: Boitempo Editorial, n. 13, maio 2009.

CHESNAIS. François. As dívidas ilegítimas - quando os bancos fazem mão baixa nas políticas públicas. Lisboa: Círculo de Leitores, 2012.

Da noção de imperialismo e da análise de Marx do capitalismo: pré/visões da crise. In: NÓVOA, Jorge (Org.). Incontornável Marx. Salvador, São Paulo: Edufba/Editora Unesp, p. 47-81, 2007.

As raízes da crise econômica mundial. In: O Olho da História, n. 18, Salvador (BA), julho de 2012. http:// oolhodahistoria.org/n18/artigos/chesnais.pdf

. A mundialização do exercito industrial de reserva. $O$ Comuneiro - revista eletrônica, n. 3, Set. 2006 Disponível em: www.ocomuneiro.com/ nr03_01_francois.htm. Acesso em 15/10/2012.

. A "nova economia”: uma conjuntura específica da potência hegemônica no contexto da mundialização do capital. Revista da Sociedade Brasileira de Economia Política. Rio de Janeiro, 7 Letras, n. 9, p. 53-85, dezembro de 2001.

Mundialização financeira e vulnerabilidade sistêmica. In: CHESNAIS. François (Coord.). A mundialização financeira - gênese, custos e riscos. São Paulo: Xamã, 1998.

COLLIN, Denis. Le cauchemar de Marx. Le capitalisme estil une histoire sans fin? Paris: Max Milo, 2009.

DUMÈNIL, Gerard; LÈVY, Dominique. Neoliberalismo - neoimperialismo. Economia e Sociedade. Campinas, Instituto de Economia, Unicamp, v. 29, p. 1-19, 2007.

DUMÈNIL, Gerard; LÈVY, Dominique. Neoliberal dynamics: a new phase? Paris: Cepremap, 2004.

FILGUEIRAS, Luiz. A crise geral do capitalismo: possibilidades e limites de sua superação. Critica marxista. São Paulo: Boitempo Editorial, n. 31, 2010.

GILL, Louis. La crise financière et monetaire et monetaire mondiale: endettement, spéculation, austerité. Québec, M Editeur, 2012.

Fundamentos y limites del capitalismo. Madrid: Editorial Trotta, 2002.

LACERDA, Antonio Correa de. Desafios da (des)ordem econômica internacional. São Paulo: SOBEET, agosto de 2012

GONÇALVES, Reinaldo. Impacto do investimento estrangeiro direto sobre renda, emprego, finanças públicas e balanço de pagamentos. Brasília, DF: Cepal/IPEA - Texto para discussão CEPAL-IPEA, 43, 2011.

LAPAVITSAS, Costas. Financialisation, or the search for profits in the sphere of circulation. Londres: University of London, Department of Economics, School of Oriental and African Studies, 2009a. (Discussion Paper n. 10).

LAPAVITSAS, Costas. Financialised capitalism: crisis and financial expropiation. Department of Economics, School of Oriental and African Studies, 2009b. (Discussion Paper n. 1).

McNALLY, David. Turbulence in the world economy. Monthly Review, New York, v. 51, n. 2, jun. 1999. Disponível em: www.monthlyreview.org/699mcnal.htm. Acesso em: outubro de 2012 .

LETIZIA, Vito. A grande crise rastejante. São Paulo, Caros Amigos, 2012.

MARX, Karl. O capital: crítica da economia política. São Paulo: Abril Cultural, 1986. (Os Economistas, livro III).

MATTICK, Paul. Economic crisis and crisis theory. In: Class against Class. [s.l.], 1974. Disponível em: www.marxists.org. Acesso em: outubro de 2012.

MILAN, Marcelo. A crise financeira nos EUA: causas, consequências e desdobramentos teóricos. Revista da Sociedade Brasileira de Economia Política. São Paulo, n. 33, p. 103-145, outubro 2012

NÓVOA, Jorge. O canto do cisne? Modernidade e barbárie. In: NÓVOA, Jorge (Org.) A história à deriva: um balanço de fim de século. Salvador: Editora da UFBA, 1993.

. Incontornável Marx. Salvador: Ed. da UFBA, 2007

PANITCH, Leo; GINDIN, Sam. From global finance to the 
nationalization of the banks: Eight Theses on the Economic Crisis. Socialist Project, E-Bulletin n. 189, 25

fev. 2009. Disponível em: www.socialistproject.ca/bullet/ bullet189.html. Acesso em: outubro de 2012.

ROLLINAT, Robert. Neoliberalismo e dilemas da privatização bancária na América Latina. In: NÓVOA, Jorge (Org.) A história à deriva: um balanço de fim de século. Salvador: Editora da UFBA, 1993.
ROLLINAT, Robert. La nouvelle histoire économique. 1997.

SHAIKH, Awar. Valor, acumulación y crisis: ensayos de economía política. Buenos Aires: Ediciones RyR, 2006. 


\section{THE FINAL STAGE OF CAPITAL. THE CRISIS AND THE DOMINATION OF FINANCE CAPITAL IN THE WORLD}

\author{
Jorge Nóvoa \\ Paulo Balanco
}

Within the limitations of this article the authors analyzed various elements of the wave of transformations which have occurred in the scope of the world's capitalist economy over recent decades. These transformations have led to measures against trends aimed at blocking and overcoming the structural crisis resulting from stagnation after a long period of post-World War II growth. In contradiction, at a time in which the changes that were introduced have proven to be powerful leveraging tools for innovation in the production and finance arenas, their content is also thoroughly regressive. Capitalism has undergone a profound transformation, but without the consolidation of a solid new base to increasingly reward big capital in order to replace the cycle which ended in the early 1970s. The "underdeveloped" and "emerging" countries reproduce, with some particularities, these contradictions under the domination of financial capital. Thus, capitalism's new model of reproduction currently shows visible limits. It prolongs the organic crisis which is developing regressions which threaten human destiny, but not without creating new bases for overcoming anti-capitalism.

KEY WORDS: Profound crisis. Financial capital. Decreasing profits. Emerging countries. Alternative base for accumulation.

\section{LA DERNIÈRE ÉTAPE DU CAPITAL. LA CRISE ET LA DOMINATION DU CAPITAL FINANCIER DANS LE MONDE}

\author{
Jorge Nóvoa \\ Paulo Balanco
}

Les divers facteurs de transformation qui ont eu lieu au sein de l'économie capitaliste mondiale au cours des dernières décennies sont analysés dans cet article. Ces transformations sont l'aboutissement des mesures prises contre les tendances visant à bloquer et à surmonter la crise structurale provoquée par le manque de croissance à long terme de l'après-deuxième guerre mondiale. Paradoxalement, alors que les changements réalisés se sont révélés être de puissants leviers innovateurs sur les plans productif et financier, ils étaient chargés aussi de contenus profondément régressifs. Le capitalisme s'est beaucoup transformé mais sans consolider une nouvelle base suffisamment forte et capable de rémunérer de manière croissante le grand capital afin de remplacer le cercle fermé au début des années 1970. Les pays "sousdéveloppés" et "émergents" reproduisent avec quelques spécificités ces contradictions sous domination du capital financier. Par conséquent le nouveau modèle de reproduction du capitalisme des temps présents affiche des limites visibles. La crise organique se prolonge et se multiplie par des régressions menaçantes pour le destin de l'humanité, sans pour autant créer de nouvelles bases capables d'un dépassement anti-capitaliste.

MotS-CLÉs: crise profonde, capital financier, bénéfices décroissants, pays émergents, base alternative d'accumulation.

Jorge Luiz Bezerra Nóvoa - Doutor em Sociologia. Professor da Universidade Federal da Babia - UFBA. Áreas de investigação: Epistemologia da razão poética e a reconstrução dos paradigmas das ciências sociais; Sobre as relações entre o cinema e a história e as representações das sociedades no cinema; Marx e a teoria do conhecimento nas ciências sociais, na história e na psicanálise; História das ciências sociais e da psicanálise, História moderna e contemporânea; História do capitalismo e dos movimentos sociais; Sociologia do conhecimento e das formas de consciência social. Publicações recentes: O problema do belo em "Morte em Veneza" e "Blow-up": tensões, conflitos e contradições no real que a estética reconstrói. In: Alcides Freire Ramos, Cléria Botelho da Costa, Rosangela Patriota. (Org.). Temas de história cultural. 1ed.São Paulo: Hucitec, 2012, v. 1, p. 184-197; "Barravento": dicotomias da cultura popular religiosa afrodescendente no cinema de Glauber Rocha. Revista Porto, v. 1, p. 70-79, 2011.

Paulo Antonio de Freitas Balanco - Doutor em Economia pela Universidade Estadual de Campinas (UNICAMP), Professor do Departamento de Economia da Universidade Federal da Bahia e atual diretor da mesma faculdade. Integra e coordena o Grupo de Pesquisa em Economia Política e Desenvolvimento, desenvolvendo pesquisas na área de Economia Política explorando o tema processos de transformação do capitalismo e seus desdobramentos, mediante os seguintes objetos de pesquisa e investigação: leis do movimento do capital, globalização e desenvolvimento econômico capitalista. Suas mais recentes publicações são: Modelo liberal-periférico e bloco de poder: política e dinâmica macroeconômica nos governos Lula, em coautoria com Luiz Filgueiras, Bruno Pinheiro e Celeste Philigret. In: Os anos Lula: contribuição para um balanço crítico 2003-2010. Rio de Janeiro: Garamond, pp. 35-69, 2010, e Instituições, políticas públicas e financiamento do desenvolvimento regional no nordeste do Brasil. Em co-autoria com Clemente Gomes de Souza e Henrique Tomé da Costa Mata. In: Revista Desenbahia, nº 17, pp. 61-88, setembro de 2012. 